\title{
GAMBARAN KUALITAS PELAYANAN KEPERAWATAN DAN PEMENUHAN KEBUTUHAN KELUARGA PASIEN DI ICU: LITERATURE REVIEW
}

\author{
Description of Nursing Care Quality and Family Needs Attainment in Intensive Care \\ Units: A literature review
}

\author{
Muhamad Pondi*, Suhaimi Fauzan**, Nita Arisanti Yulanda** \\ * Mahasiswi Prodi Keperawatan,Fakultas Kedokteran, Universitas Tanjungpura, Pontianak \\ ** Dosen Keperawatan, Fakultas Kedokteran, Universitas Tanjungpura, Pontianak \\ Jl. Prof. Dr. H. Hadari Nawawi, Pontianak \\ Email: pondyputra1997@gmail.com
}

\begin{abstract}
ABSTRAK
Latar Belakang: Pelaksanaan pelayanan keperawatan di ruang Intensive Care Unit (ICU) lebih memfokuskan kepada perawatan pasien kritis, sehingga keluarga pasien yang menunggu merasa terabaikan. Hal ini akan berdampak terhadap kualitas pelayanan keperawatan yang kurang baik. Masalah yang sering terjadi oleh keluarga di ruang ICU ialah kurang terpenuhi pemenuhan kebutuhan keluarga pasien. Implementasi yang dapat perawat lakukan ialah mengidentifikasi dan memenuhi kebutuhan keluarga yang menjadi prioritas.

Tujuan: Mengidentifikasi gambaran kualitas pelayanan keperawatan dan pemenuhan kebutuhan keluarga pasien di ICU.

Metode: Jenis penelitian literature review dengan teknik analisis data menggunakan content analyis, artikel diperoleh dari database Google Scholar, PubMED, neliti.com, Portal Garuda dan Research Gate, menggunakan kata kunci: kualitas pelayanan keperawatan, Intensive Care Unit, kebutuhan keluarga, family needs, quality, nursing care. Ekstraksi data meliputi nama pengarang, tahun, negara,tujuan, reponden, desain, finding/temuan.

Hasil: Dari hasil literature review ditemukan tujuh artikel yang sesuai dengan kriteria. Analisis menunjukkan bahwa pelaksanaan kualitas pelayanan di ICU dan pemenuhan kebutuhan keluarga sudah rata-rata baik. Pasien dan keluarga merasa puas atas pelayanan keperawatan, terutama mengenai daya tanggap dan rasa empati. Kebutuhan yang menjadi prioritas ialah jaminan pelayanan dan informasi.

Kesimpulan: Kualitas pelayanan keperawatan di ICU telah baik dari unsur daya tanggap dan empati perawat. Pemenuhan kebutuhan keluarga diprioritaskan ialah jaminan pelayanan dan informasi.
\end{abstract}

Kata Kunci: Kualitas pelayanan, kebutuhan keluarga, Intensive Care Unit

Referensi: 55 (2012-2019) 


\begin{abstract}
Background: Nursing care interventions in the intensive care units (ICUs) are mainly focused on critical care, while the family who is waiting for the ill is often neglected. This may negatively affect the quality of nursing care itself. The most frequently encountered nursing problem found in the ICUs is the deficient family needs attainment. The possible nursing care interventions to overcome this problem are identifying and meeting the most prioritized family needs.
\end{abstract}

Aim: To investigate the quality of nursing care and family needs attainment in intensive care units.

Method: The literature review was performed by searching articles published in Google Scholar, PubMed, neliti.com, Portal Garuda, and Research Gate, using keywords: kualitas pelayanan keperawatan, intensive care unit, kebutuhan keluarga, family needs, quality, nursing care. The data extraction includes the authors' names, publication years, country names, study designs, and main findings, The content analysis method was used in this study.

Result: The literature review found seven eligible articles. The analysis shows that nursing care and family needs attainment in the ICUs were good. Patients and families were satisfied with the nursing care given, especially the nurses' responsiveness and empathy. The most prioritized needs were service and information assurance.

Conclusion: The quality of nursing care in the ICUs was good, based on the nurses' responsiveness and empathy. The most prioritized family need was service and information assurance.

Keywords: service quality, family needs, intensive care unit

Reference:55 (2012-2020) 


\section{PENDAHULUAN}

Intensive Care Unit (ICU) merupakan sebuah unit pelayanan perawatan dalam kegiatannya selalu padat menangani dan merawat pasien yang kondisinya kritis dengan penatalaksaan bantuan hidup serta pengawasan intensif. beban kerja yang sibuk di ruang Intensive Care Unit (ICU) perawat lebih memfokuskan pelayanan kepada pasien dibandingkan ke keluargnya yang sedang menunggu di rung tunnggu (Hardayanti, Meliala, \& Santoso, 2012). Kemampuan memberikan pelayanan Keperawatan membutuhkan kompetensi yang baik khususnya di ruang perawatan intensif, menurut penelitian Lam (2015) menyatakan bahwa kepuasan kebutuhan keluarga di ruang perawatan intensif salah satunya dipengaruhi oleh kualitas pelayanan keperawatan yang diberikan kepada pasien dan keluarga saat dirumah sakit (Lam, et al., 2015).

Dalam penelitian yang dilakukan oleh AL-Mutair (2013) kebutuhan keluarga pasien di perawatan intensif tidak selalu terpenuhi semuanya oleh pelayanan keperawatan, keluarga menyatakan bahwa kebutuhan yang sangat terpenting yaitu jaminan, kebutuhan akan kedekatan, kenyamanan dan kebutuhan dukungan. Keluarga mengungkapkan perawat sangat berperan penting dalam memenuhi kebutuhan keluarga di perawatan intensif (AlMutair, Plimmer, O'Brien, \& Clerhan, 2013).

Penelitian yang dilakukan Hashim dan Hussin (2012) disalah satu ruangan perawatan intensif salah satu dirumah sakit Malaysia, keluarga inti seperti orang tua yang hanya dapat berada diruangan ICU untuk mendampingi pasien. Keluarga lain yang tidak berikatan inti dengan pasien tidak dapat melakukan pergantian penjagaan dan kurang mendapatkan informasi mengenai kondisi pasien. Keluarga lebih memilih untuk mendapatkan informasi dari dokter yang bersifat komprehensif dibandingkan dengan perawat yang hanya memberikan informasi berdasarkan pengamatan dan kondisi pasien di ICU. Keluarga berpegang teguh dalam mendapatkan informasi setidaknya sekali sehari tentang kondisi pasiennya yang diberikan oleh dokter dan perawat, dalam situasi jadwal kerja dokter dan perawat yang berat, anggota keluarga akan berterima kasih jika dokter dan perawat memperbaharuinya dengan kondisi pasien setidaknya sekali sehari (Hashim \& Hussin, 2012).

Kepuasan kualitas pelayanan keperawatan bergantung kebutuhan keluarga dipengaruhi oleh budaya di ICU dirumah sakit tersebut, didalam rumah sakit tipe B masih bergantung dengan budaya, sehingga untuk menerapkan konsep baru masih sangat sulit. Kebutuhan keluarga tentang kenyamanan dan dukungan masih dalam taraf rendah karena keluarga lebih mengorbankan ketidaknyamanan untuk kebutuhan pasiennya. Keluarga berharap Kebutuhan juga harus diutamakan dan keluarga memiliki harapan tentang fasilitas kenyaman dan dukungan emosional bersama dengan kemajuan perawatan di ICU rumah sakit (Min, et al., 2018).

Hasil penelitian dalam kualitas pelayanan keperawatan terhadap kepuasan keluarga sebagian besar baik (75\%) dari 24 responden, tidak baik sebanyak (25\%) dari 8 reponden. Namun dalam tingkat kepuasan keluarganya, masih terdapat rerponden yang menyatakan kurang puas $(21,9 \%)$ dari 7 reponden serta $(12,5 \%)$ dari 4 reponden menyatakan tidak puas. Keluarga pasien merasa kurang merasakan hasil dalam pelayanan keperawatan yang tidak sesuai dengan harapan keluarga (Retnaningsih, Aini, \& Yulianti, 2017).

Data dari penelitian dilakukan oleh Lukmanulhakim\&Firdaus (2018) di ruangan ICU RSUD DR. Drajadat 
Prawiranegara Serang menyatakan secara keseluruhan dari 40 responden, terdapat kebutuhan keluarga tidak terpenuhi sebanyak $45 \%$ selama mengunggu pasien di ruang tunggu. Kebutuhan yang tidak terpenuhi mengenai informasi $35 \%$, dukungan mental $57,5 \%$, rasa nyaman $40 \%$, kedekatan dengan pasien $52,5 \%$ dan jaminan Pelayanan 37,5\% (lukmanulhakim \& Firdaus, 2018).

Penelitian dari Silva (2017) menjelaskan dalam ruangan perawatan intensif lebih berfokus pada kebutuhankebutuhan fisik pasiennya, keluarga merasakan terabaikan oleh pelayanan keperawatan. Kebutuhan Keluarga kurang di prioritas dapat menyebabkan kecemasan,stres dan depresi (Silva, Fortunatti, Munoz, \& Rojas, 2017).

Kebutuhan informasi jika tidak diberikan oleh perawat atapun tenaga kesehatan lainnya setiap harinya, maka keluarga pasien mengalami kegelisahan, kebingungan bahkan kecemasan. Rasa khawatir yang dialami keluarga pasien juga terjadi jika dalam pembatasan kedekatan dengan pasien, karena keluarga berperan untuk kebutuhan pendekatan kondisi fisik dari pasiennya. Perawat sangat berperan penting dalam memberikan infomasi dan berkomunikasi dengan keluarga atas keadaan kondisi pasien, karena keluarga pasien sendiri tidak selalu bisa melihat dan berada bersama pasien diruangan perawatan intensif (Halimuddin \& Atika, 2018).

Perawat berperan dalam memenuhi kebutuhan keluarga untuk mengurangi kecemasan dan stres, tindakan yang dapat dilakukan perawat untuk keluarga yaitu sebagai advokator untuk menjelaskan informasi yang baik serta dapat di terima mengenai kondisi pasien. Perawat juga dapat memberikan ketenangan kepada keluarga agar tetap psikologis dan fisik tidak terganggu, dalam ruangan perawatan intensif perawat merupakan orang layanan kesehatan yang sangat dekat dan lama berasa bersama pasien, jadi keluarga sangat bergantung dalam pemenuhuan informasi tentang kondisi pasien (Wardah, 2013).

Penelitian oleh Ana Fadilah dan Wahyu Yusianto (2019) Hubungan kualitas pelayanan pelayanan keperawatan keperawatan dengan kepuasan pasien rawat inap bedah di RSUD dr. Loekmono Hadi Kudus menyatakan terdapat hubungan antara kualitas pelayanan dan kepuasan pasien dengan nilai $\mathrm{p}$ value $(0,000)$, kualitas pelayanan keperawatan yang disediakan di rumah sakit memiliki kategori baik, maka pasien tersebut akan merasa puas (Fadilah \& Yusianto, 2019). Penelitian mengenai hubungan pelayanan keperawatan dengan kepuasan pasien BPJS rawat inap di Rumah Sakit Umum Herna Medan menyatakan mengenai pelayanan keperawatan 28 dari 60 responden merasa kurang $(46,7 \%)$ tentang ketanggapan perawat dalam melayani keluhan pasien dan 44 responden menyatakan kurang puas $(73,3 \%)$ dalam mengenai BPJS (Frida \& Putri, 2019). Penelitian yang dilakukan I Putu Krisna Widya Nugraha dan Dody Setyawan mengenai gambaran kebutuhan keluargga pasien di ruang instalasi gawat darurat, didapatkan kebututuhan komunikasi dengan nilai mean 31,2 dimana responden memerlukan informasi-informasi menengenai kondisi pasien.

Penelitian yang dilakukan Lukmanulhakim dan Winda Firdaus (2018) pemenuhan kebutuhan keluarga pasien kritis diruang Intensive Care Unit (ICU) RSUD dr. Dradjat Prawiranegara Serang, kebutuhan keluarga yang tidak terpenuhi sebanyak $45 \%$ dan terpenuhi sebanyak 55\%. Penelitian mengenai Kebutuhan Keluarga pasien yang dirawat di Intensive Care Unit (ICU) didapatkan hasil kebutuhan keluarga mengenai informasi yang paling menjadi prioritas utama dimana keluarga memerlukan informasi pasien secara komprehensif. 
Setelah peneliti melihat hasil literatur review penelitian sebelumnya, peneliti menemukan data hasil penelitian mengenai pelayanan keperawatan di ruang Intensive Care Init (ICU) belum banyak di teliti di Indonesia menggunakan hasil review artikel, mengenai kebutuhan keluarga juga perlu di identifikasi dalam pemenuhan kebutuhan keluarga pasien kepada perawat di ruangan ICU,maka peneliti tertarik melakukan penelitian dengan metode Literature Review mengenai gambaran kualitas pelayanan keperawatan dan pemenuhan kebutuhan keluarga pasien di ICU. Peneliti juga memiliki kendala dalam melaksanakan pengambilan data primer di rumah sakit khususnya di ruangan Intensive Care Unit (ICU) yang akan digunakan sebagai bahan penelitian ini yang dikarenakan pada saat ini masih terjadi wabah pandemi, oleh sebab itu peneliti merubah dalam metode penelitian ini menjadi literature review.

\section{METODE}

Dalam penelitian ini menggunakan desain jenis penelitian ilmiah literature review yaitu menganalisis berbagai artikel-artikel yang valid dan relevan dengan topik yang peneliti akan review.

Jenis data yang digunakan yaitu data sekunder ialah artikel yang diperoleh dari internet dan web resmi yang membahas kualitas pelayanan keperawatan dan kebutuhan keluarga di icu.

Strategi penelusuran artikel dalam penelitian ini menggunakan kata kunci "kualitas pelayanan keperawatan," Intensive Care Unit", "kebutuhan keluarga", "family needs", "quality","nursing care".

Penelusuran artikel dalam penelitian ini mengunakan Database akademik yaitu: Google Scholar, PubMED, neliti.com, Portal Garuda dan ResearchGate.

Kriteria inklusi penelitian ini ialah: artikel penelitian dengan data penelitian primer dan sekunder, artikel penelitian yang penelitiannya di Indonesia, artikel penelitian yang digunakan rentan waktu 5 tahun terakhir (2016-2020), dan artikel penelitian yang membahas mengenai kualitas pelayanan keperawatan dan kebutuhan keluarga pasien di Intensive Care Unit (ICU). Kriteri ekslusi penelitian ini ialah artikel penelitian yang menampilkan informasi tidak lengkap, buku, skripsi, dan tesis.

Hasil pencarian dan seleksi studi penelitian dari Database akademik didapatkan 787.558 artikel sesuai kata kunci, kemudian didapatkan hasil screening artikel didapatkan hasil yang sesuai dengan kriteria inklusi sebanyak 8 artikel.

Ekstraksi data yang digunakan untuk mengisi analisis artikel dalam penelitian ini ialah: nama pengarang, tahun, negara, tujuan, partisipan/responden,desain, dan finding/temuan.

Analisis data dalam penelitian ini menggunakan teknik conten analysis dengan mengamati fenomena hasil isi penelitian dengan mengidentifikasi sesuai topik peneliti secara mendalam mengenai hasil penelitian yang ditemukan (Ahmad,2018).

\section{HASIL}

Kualitas Pelayananan Keperawatan di ICU

a. Perilaku Caring Perawat

b. Tele-ICU

c. Penerapan Proses Keperawatan Ida Jean Orlando

Pemenuhan Kebutuhan Keluarga Pasien di ICU
a. Kebutuhan Jaminan Pelayanan Keperawatan
b. Kebutuhan Informasi
c. Kebutuhan Kedekatan
d. Kebutuhan Rasa Nyaman
e. Kebutuhan Dukungan 


\section{PEMBAHASAN}

\section{Kualitas Pelayanan Keperawatan di Intensive Care Unit (ICU)}

Peningkatan kualitas pelayananan keperawatan di ruang Intensive Care Unit (ICU) salah satunya dengan cara bagaimana perawat dalam melakukan pelayanan kepada keluarga dan pasien, penelitian oleh (Setyowati, Sulisetyawati, \& Saelan, 2019) terdapat hubungan perilaku caring perawat dengan kualitas asuhan keperawatan pasien di ruang ICU RSUD dr. Moewardi diperoleh nilai signifikasi $\mathrm{p}$ value $=0,000$ dan nilai korelasi $r=0,664$. Perilaku caring yang diterapkan setiap perawat dalam melakukan pelayanan keperawatan di ICU akan meningkatkan kualitas pelayanan keperawatan yang tinggi, perilaku caring yang baik dan sering dilakukan oleh perawat tidak hanya berorientasi kepada pasien saja, melainkan kepada keluarga pasien yang sedang menunggu di ruang tunggu, kepedulian perawat akan membuat keluarga pasien tenang dan merasakan di perhatikan. Di dukung penelitian oleh (Shalaby, Janbi, Mohammed, \& Alharthi, 2018) perawat yang berkerja di ruang perawatan kritis ICU memiliki tingkat perilaku caring yang tinggi $(96,8 \%)$, kesadaran perawat dalam berperilaku caring dikarenakan pasien bersifat rentan sedang kondisi kritis membutuhkan perlindungan dan keselamatan di ruang perawatan ICU.Pentingnya caring di ruang perawatan ICU merupakan aspek fisiologis perawatan dan bantuan kepada pasien kritis dan keluarga pasien agar mendapatkan kepuasan terhadap pelayananan yang diberikan. Berbeda dengan hasil penelitian oleh (Hardayani \& Lukmanulhakim, 2019) menyatakan pelayanan keperawatan di ICU mengenai perilaku caring oleh perawat masih kurang peduli sebanyak $41 \%$, kurangnya respon dari perawat ketika keluarga dan pasien saat bertanya mengenai informasi.
Hasil analisis menurut peneliti menununjukkan bahwa Kualitas pelayananan keperawatan di ICU telah baik dari unsur daya tanggap (responsiveness) dan empati (empathy) perawat yang melakukan perilaku caring dan kepedulian yang tinggi kepada pasien dan keluarga pasien. Sikap empati terhadap seseorang individu merupakan bentuk pemahaman lebih mengenai apa yang dirasakan oleh pasien yang sedang sakit (Sinclair, et al., 2017).

Penelitian oleh (Rizany \& Hariyati, 2017) menyatakan peningkatan kualitas pelayanan keperawatan di ICU menggunakan Tele-ICU, yang memudahkan perawat dan dokter berkolaborasi dalam menangani pasien, dapat mengurangi angka mortalitas, keparahan pasien dan mengurangi waktu tinggal pasien yang dirawat di ICU.disisi lain mengenai Tele-ICU memiliki banyak hambatan dikarenakan perawat dan tenaga kesehatan lainnya masih kurang memahami mengenai teknologi Tele-ICU yang membuat pelayanan keperawatan menjadi terhambat, hasil penelitian oleh (Hoonakker \& Carayon, 2018) hambatan pada Tele-ICU di ruang perawatan ICU yaitu perawat menjadi kurang berkomunikasi secara langsung dengan staff ICU lainnya, kurangnya pengalaman perawat dalam penggunaan Tele-ICU. hasil analisis menurut peneliti bahwa peningkatan kualitas pelayanan keperawatan pada penggunaan Tele-ICU memiliki hambatan dari perawat yang kurang berpengalaman dan belum terlatih dalam pelaksanaan Tele-ICU di ruang perawatan intensif. Tingkat pengetahuan dan pemahaman perawat memiliki pengaruh dalam pelayanan perawatan, pemahaman yang baik akan membuat pelayanan keperawatan menjadi rasional dan tepat serta berpikir kritis (Oyira, James, \& E.R, 2016).

Hasil penelitian oleh (Zainal, Ake, \& Pasinringi, 2019) terdapat hubungan proses keperawatan Orlando dengan peningkatan kualitas pelayanan 
keperawatan mengenai kepuasan pasien di ruang ICU dan IGD dengan nilai $(0,000)$. Tanggung jawab perawat dalam melakukan pelayanan keperawatan telah baik $(87,60 \%)$. Perawat dalam melaksanakan tanggung jawabnya bersifat komprehensif sepenuhnya merawat pasien di ruang perawatan intensif. tanggung jawab seorang perawat dalam peningkatan pelayanan keperawatan di tidak hanya berfokus kepada kasien, perawat berperan penting dalam memberikan dukungan kepada keluarga pasien. sejalan dengan penelitian oleh (Gaeeni, Farahani, Seyedfatemi, \& Mohamammadi, 2015)dukungan dan empati dari para perawat dapat membantu keluarga pasien menghadapi dalam situasi kritis di ruang ICU dan menciptakan sikap positif antara anggota keluarga serta mengembalikan kehidupan mereka ke keadaan normal. Menurut peneliti dalam meningkatkan kualitas pelayanan keperawatan di ruang Intensive Care Unit (ICU) dapat dilaksanakan melalui proses caring perawat, memanfaatkan Tele-ICU, dan proses keperawatan Orlando. Proses caring perawat yang dilaksanakan di ruang Intensive Care Unit (ICU) kepada keluarga pasien, keluarga akan merasa peduli dan diperhatikan sepenuhnya selama menunggu pasien yang sedang dirawat, perilaku caring perawat diutamakan dalam pelayanan sehingga pasien dan keluarga akan merasakan puas apa yang telah diterima. Pemanfaatkan Tele-ICU menudahkan perawat dalam melakukan kolaborasi dengan tenaga kesehatan dan akan mengurangi jangka perawatan bagi pasien, menggunakan Tele-ICU masih memiliki hambatan mengenai kurangnya pemahaman oleh perawat tentang teknologi dan kurangnya berinteraksi secara langsung dengan staff medis lainnya. Menurut peneliti proses penerapan caring perawat dan proses keperawatan Orlando sangat berperan penting dalam meningkatkan kualitas pelayanan keperawatan di Intensive Care
Unit (ICU) karena tidak memiliki kendala banyak seperti pemanfaatan Tele-ICU. Caring perawat dan keperawatan Orlando ini masuk dalam unsur kualitas pelayanan daya tanggap (responsiveness) dan empati (empathy) perawat yang dilihat dari perilaku perhatian sikap empati dan kepedulian yang tinggi kepada pasien dan keluarga pasien.

\section{Pemenuhan Kebutuhan Keluarga Pasie di Intensive Care Unit (ICU) \\ Hasil penelitian dari (Atika \&} Halimuddin, 2018) pemenuhan kebutuhan yang keluarga perlukan saat menunggu pasien perawatan yang paling utama yaitu kebutuhan jaminan pelayanan dengan nilai mean (3.72), kebutuhan informasi (3.72), kebutuhan kedekatan dengan pasien (3.10), kebutuhan rasa nyaman (3.06), kebutuhan dukungan mental (2,78), kebutuhan jaminan pelayanan merupakan kebutuhan yang paling penting bagi keluarga pasien yang sedang di rawat di ruang Intensive Care Unit (ICU). Keluarga berharap mendapatkan pelayananan yang terbaik dari dokter maupun perawat dan mengetahui tindakan yang telah diberikannya kepada pasien. Sejalan dengan penelitian dari (Alsharari, 2019) bahwa kebutuhan yang paling penting yaitu kebutuhan akan jaminan dengan nilai rata-rata (3.62), informasi $(3,47)$, kedekatan $(3,34)$, kenyamanan (3.01), dan dukungan $(2,91)$ , kebutuhan jaminan pelayanan merupakan kebutuhan yang telah terpenuhi bagi keluarga yang di lihat dari keluarga telah merasakan pelayanan yang terbaik bagi pasien, pedulinya petugas kesehatan kepada keluarga dan keluarga diberi tentang rencana tindakan yang akan dilakukan. hasil analisis menurut peneliti menunjukkan pemenuhan jaminan pelayanan yang diberikan akan membuat keluarga pasien masih memiliki harapan kepada orang yang yang di cintai dan keluarga merasakan 
kenyamanan di saat pasien merasa kecemasan, keluarga inti merupakan orang yang sangat berperan dalam akan kesembuhan pasien, seperti orang tua, suami atau istri, dan anak pasien. Analisis menurut ini didukung oleh penelitian ( Zainal M, Sasikala Ma, \& Nurfarieza Se, 2016) keluarga mempercayai kepada tenaga kesehatan tentang pemenuhan kebutuhan jaminan pelayanan yang diberikan secara profesional keperawatan, keluarga inti seperti pasangan hidup,orang tua, dan anak berperan penting dalam mengharapkan jaminan pelayanan yang terbaik.

Hasil penelitian oleh (Alfi\&Fitri, 2019) mengenai priortias kebutuhan keluarga pasien di ICU yaitu kebutuhan Informasi, kemudian diikuti kebutuhan kedekatan, kebutuhan dukungan, kebutuhan keterlibatan, dan kebutuhan mengetahui perawatan yang diterima pasien. Kebutuhan informasi yang di inginkan oleh keluarga pasien yaitu bagaimana perkembangan keadaan pasien yang telah dirawat di tuang ICU secara menyeluruh, hasil analisis menunjukkan bahwa kebutuhan informasi diperlukan keluarga, karena di ruangan perawatan intensif keluarga tidak sepenuhnya melihat perawatan yang diberikan. Sejalan dengan penelitian (Almagharbeh, Alhassan, Motlaq, \& Almagarbeh, 2019) pemenuhan kebutuhan prioritas bagi keluarga pasien yaitu kebutuhan informasi untuk mengetahui bagimana pasien dirawat secara medis dengan nilai rata-rata 3.67. Hasil analisis menurut peneliti menyatakan bahwa kebutuhan informasi yang menjadi prioritas keluarga pasien karena kebutuhan tersebut belum sepenenuhnya terpenuhi oleh dokter dan perawat yang menjadi kewajiban dalam betugas di ruang ICU. Di dukung penelitian dari (Al-Mutair, Plimmer, O'Brien, \& Clerhan, 2013) studi kualitatif hasil wawancara, keluarga mengatakan kurangnya informasi yang jujur dan keluarga tidak mengetahui prognosis anggota keluarga yang sakit dari pihak ruang ICU.

Hasil penelitian dari (lukmanulhakim \& Firdaus, 2018) pemenuhan kebutuhan yang sangat penting dan telah terpenuhi yaitu kebutuhan informasi sebesar 65\%, analisis dari hasil penelitian ini bahwa terpenuhi nya kebutuhan informasi kepada keluarga pasien akan berdampak positif dalam pengambilan keputusan oleh keluarga tentang rencana kedepannya yang telah di informasikan oleh dokter dan perawat. Hasil analisis menurut peneliti menunjukkan pemenuhan kebutuhan informasi yang diberikan oleh perawat kepada keluarga pasien menjadikan keluarga inti mendapatkan perkembangan terbaru mengenai bagaimana pasien di rawat, perkembangan yang terjadi pada pasien, dan mengenai kondisi kritis atau kematian pasien, keluarga inti yang membutuhkan informasi yaitu orang tua pasien dan keluarga pasien yang berjenis kelamin perempuan. Sejalan hasil penelitian (Aziz-Abdel, Ahmed Sayed, \& Younis, 2017) keluarga perempuan lebih dekat bersama pasien di ruang ICU dan sepertiga hubungan dari pasien yaitu orang tua dari pasien yang selalu membutuhkan informasi mengenai diagnostik dan prognosis pasien. Di dukung penelitan dari (Dibsh, Gohal, \& Kherat, 2019), Keterlibatan anggota keluarga di ruang Intensive Care Unit (ICU) mencegah terjadinya miskomunikasi perbedaan persepsi antara perawat dan keluarga yang merupakan aspek penting dari perawatan pasien serta memperkuat hubungan dengan keluarga. Berbeda dengan hasil penelitian dari (Chhetri \& Thulung, 2018) kebutuhan jaminan menjadi prioritas pertama di bandingkan kebutuhan informasi. Keluarga ingin mengetahui pelayanan perawatan yang diberikan, untuk mengenai informasi harian tentang pasien keluarga menjadi prioritas ke lima. 
Hasil penelitian dari (Apriyanti \& Adawiyah, 2018) lima pemenuhan kebutuhan keluarga yang di prioritaskan saat di ruang perawatan intensif yaitu kebutuhan jaminan tentang hasil perawatan dengan nilai 3,75 , persamaaan sudut pandang dari keluarga pasien dan perawat yang sama-sama memprioritaskan tetang jaminan perawatan. Di dukung penelitian oleh (Fortunatti, 2014) kebutuhan jaminan menjadi kebutuhan terpenting dan harus terpenuhi bagi keluarga, aspek-aspek dari kebutuhan keluarga tentang jaminan yang perlu terpenuhi untuk keluarga pasien yaitu mengenai tanggapan dari dokter dan perawat dapat di sampaikan dengan tulus kepada keluarga, keluarga ingin mengetahui prognosis pasien yang di rawat, merasakan staf pelayanan kesehatan memperhatikan pasien, memastikan perawatan yang terbaik, dan mengetahui penjelasan secara fakta,spesifik serta dapat memahami istilah asing yang di sampaikan perawat dan dokter. Hasil analisis menurut peneliti menyatakan bahwa dalam memenuhi pemenuhan kebutuhan keluarga secara keseluruhan setiap aspek-aspek bagian dari kebutuhan keluarga, perawat di tuntut paham bagaimana karakter setiap individu atau keluarga pasien dalam memberikan pelayanan keperawatan. Agar pemenuhan kebutuhan keluarga dapat terpenuhi dalam setiap aspeknya, salah satunya dengan cara perawat memiliki kemampuan keterampilan komunikasi yang efektif yang disampaikan kepada keluarga yang akan menciptakan hubungan timbal balik yang interaktif, menjelaskan dengan cara yang mudah dan sederhahana akan membuat keluarga menjadi terlibat dengan perawatan pasien (Fateel \& O'Neill, 2015).

Menurut peneliti pemenuhan kebutuhan keluarga pasien di Intensive Care Unit (ICU) yang sangat penting dan menjadi prioritas keluarga yaitu kebutuhan jaminan pelayanan dan kebutuhan informasi. Pentingnya kebutuhan jaminan pelayanan yang diberikan kepada keluarga pasien akan membuat mereka masih memiliki harapan kepada pasien yang di cintainya, keluarga pasien merasakan kenyamanan disaat situai yang sedang cemas.

Menurut peneliti pemenuhan kebutuhan jaminan pelayanan yang dibutuhkan keluarga pasien menengenai respon tanggapan dari dokter dan perawat yang disampaikan dengan tulus, prognosis pasien yang di rawat, keinginan keluarga kepada staff pelayanan selalu memperhatikan pasien yang di rawat dan perawatan yang diberikan itu terbaik, penjelasan secara fakta serta spesifik. Pemenuhan kebutuhan informasi juga menjadi prioritas keluarga pasien yang dibutuhkan keluarga, karena keluarga ingin mengetahui perkembangan terbaru dari pasien serta keluarga juga tidak sepenuhkan berada bersama pasien. Keluarga inti seperti orang tua, anak dan pasangan merupakan keluarga yang selalu diprioritaskan dalam pemenuhan kebutuhan jaminan dan informasi, pihak perempuan juga lebih sering ingin mengetahui informasi perkembangan karena pihak perempuan lebih dekat bersama pasien saat dalam perawatan.

\section{IMPLIKASI}

Kualitas pelayanan keperawatan di ruang ICU telah baik dilakukan oleh perawat yang bertugas. Proses pelaksaanaan peningkatan kualitas pelayanan keperawatan di ruang Intensive Care Unit (ICU) lebih ditekankan oleh perawatan untuk berperilaku caring kepada keluarga dan pasien. Hasil penelitian ini memberikan pemahaman kepada perawat dalam pelayanan keperawatan yang berkualitas dapat dilakukan dengan cara berperilaku caring, memiliki sikap peduli dan empati kepada keluarga dan pasien. Hasil penelitian ini yang menggunakan metode literature review dapat menjadikan bahan 
penelitian selanjutnya mengenai kualitas pelayanan keperawatan dan kebutuhankebutuhan keluarga yang perlu di identifikasi lebih mendalam.

Keterampilan dan tingkat pengetahuan yang baik akan meningkatkan kualitas pelayanan keperawatan menjadikan hasil proses keperawatan yang rasional dan berpikir kritis secara komprehensif di ICU. Tanggung jawab seorang perawat berperan penting terhadap kualitas pelayanan yang bermutu,dapat di lihat dari bagaimana perawat memiliki sifat rasa empati dan dukungan kepada keluarga dan pasien dalam masa kritis. Pemenuhan kebutuhan keluarga pasien di Intensive Care Unit (ICU) yang menjadi priotias yaitu kebutuhan jaminan pelayanan dan kebutuhan informasi, dan telah terpenuhinya kebutuhan keluarga pasien tersebut selama menunggu di ruang ICU, membuat keluarga merasakan kepuasan terhadap pelayanan yang diberikan oleh perawat. Keluarga pasien merasa percaya kepada perawat dan tenaga medis lainnya memberikan jaminan pelayanan perawatan kepada pasien yang terbaik, dan keluarga mendapatkan informasi sesuai fakta apa yang telah di dilaksanakan dari perawat mengenai tindakan dan perkembangan terkini dari perawat. Peranan tanggung jawab dari perawat dalam meningkatkan kualitas pelayanan keperawatan dan pemenuhan kebutuhan di setiap masingmasing keluarga pasien harus memiliki kemampuan mengidentifikasi dan terampil dalam pemenuhan kebutuhan yang diperlukan oleh setiap keluarga saat menunggu pasien di ICU karena setiap individu berbeda kebutuhannya dengan yang lain. perawat juga harus selalu melibatkan keluarga dalam pengambilan keputusan mengenai perkembangan pasien, keluarga inti seperti pasangan hidup, orang tua dan anak memiliki peranan penting dalam proses perawatan pasien.

\section{KELEBIHAN \\ DAN \\ KETERBATASAN PENULISAN}

Kelebihan penelitian ini yaitu merupakan penelitian yang menggunakan metode sistematik literature review kualitas mengenai pelayananan keperawatan dan pemenuhan kebutuhan keluarga pasien di ICU yang sumbernya dari pengumpulkan artikel data primer dan sekunder, menyajikan bagimana bentuk kualitas pelayanann keperawatan di ICU dan menjelaskan kebutuhan keluarga pasien selama di ruang tunggu. Penulisan penelitian ini membahas hasil penelitian di Indonesia dan menjadikan wawasan yang bermanfaat bagi pelaksanaan asuhan keperawatan yang berkualitas, berfokus juga kepada pemenuhan kebutuhan yang keluarga prioritaskan.

Ketebatasan penulisan penelitian ini yaitu tidak meneliti artikel yang dari penelitian internasional, dan murni peneliti hanya membahas penelitian fokus di Indonesia, sehingga peneliti memiliki keterbatasan dalam pencarian hasil penelitian artikel yang di Indonesia karena masih terbatasnya hasil-hasil penelitian dari peneliti sebelumnya yang membahas kualitas pelayanan keperawatan dan pemenuhan kebutuhan keluarga pasien di ICU.

\section{KESIMPULAN DAN SARAN}

\section{Kesimpulan}

Berdasarkan penelitian dan pembahasan mengenai gambaran kualitas pelayanan keperawatan dan pemenuhan kebutuhan keluarga pasien di ICU: Literature Review dapat disimpulkan:

a. Peningkatan kualitas pelayanan keperawatan di Intensive Care Unit (ICU) dapat dilakukan dengan cara perilaku caring perawat, pemanfaatan Tele-ICU, dan penerapan proses keperawatan Ida Jean Orlando. Kualitas pelayanan keperawatan di Intensive Care Unit (ICU) telah baik dari unsur daya tanggap dan empati perawat. 
b. Pemenuhan kebutuhan keluarga pasien di Intensive Care Unit (ICU) yang keluarga butuhkan selama menunggu di ruangan meliputi : Kebutuhan jaminan pelayanan keperawatan, kebutuhan informasi, kebutuhan kedekatan, kebutuhan rasa nyaman dan kebutuhan dukungan. Pemenuhan kebutuhan keluarga pasien yang menjadi prioritas ialah kebutuhan jaminan pelayanan dan kebutuhan informasi.

Saran

a. Bagi Pendidikan

Penelitian ini diharapkan dapat menjadi salah satu bahan ajar dalam melengkapi kurikulum yang disesuaikan dengan perkembangan di bidang keperawatan kritis mengenai pemenuhan kebutuhan keluarga pasien di Intensive Care Unit (ICU).

b. Bagi Rumah Sakit

Hasil penelitian ini diharapkan dapat bermanfaat bagi rumah sakit khususnya di ruang Intensive Care Unit (ICU) dalam proses peningkatan kualitas pelayanan keperawatan dan memenuhi pemenuhan kebutuhan keluarga pasien yang menjadi prioritas selama menunggu diruangan ICU.

c. Bagi Penelitian Selanjutnya

Penelitian ini diharapkan memberikan informasi dan data dasar untuk melaksanakan penelitian lelih mendalam mengenai faktor-faktor apa saja yang mempengaruhi kualitas pelayanan pelayanan keperawatan dan pemenuhan kebutuhan keluarga pasien di Intensive Care Unit (ICU)

\section{DAFTAR PUSTAKA}

Hardayanti, F., Meliala, A., \& Santoso, B. (2012). Nursing Errors di unit perawatan intensif. Jurnal Managemen pelayanan kesehatan, 15(4), 194-197. Retrieved Januari 28, 2020, from https://media.neliti.com/media/p ublications/22572-ID-nursingerrors-di-unit-perawatanintensif.pdf

lam, so, Li, Ng, Lui, Heyland, \& Yan. (2015). Intensive Care Unit Family Statisfaction Survey. Hong Kong Medical Journal, 21(5), 435-443. doi:https://doi.org/10.12809/hk mj144385

Al-Mutair, S. A., Plimmer, V., O'Brien, A., \& Clerhan, R. (2013). Family Needs And Involvement In The Intensive Care Unit : A literatur Review. Journal of Clinical Nursing, 22. doi: doi: 10.1111/jocn. 12065

Hashim, F., \& Hussin, R. (2012). Family Needs of Patient Admitted to Intensive Care Unit in a Public Hospital. Procedia - Social and Behavioral Sciences , 36, 103111. Retrieved 4 23, 2019, from https://www.sciencedirect.com/s cience/article/pii/S18770428120 0479X

lukmanulhakim, \& Firdaus, W. (2018). Pemenuhan Kebutuhan Keluarga Pasien Kritis di Ruang Intensive Care Unit (ICU) RSUD DR. Drajat. Jurnal Keperawatan dan Kebidanan, 9(1), 104-110. doi:DOI: 10.26751/jikk.v9i1.379

Silva, R., Fortunatti, P., Munoz, M., \& Rojas, A. (2017). The needs of the relatives in the adult intensive care unit: Cultural adaptation and psychometric properties of the ChileanSpanish version of the Critical Care Family Needs Inventory. 
Intensive Critical Care Nursing, 123-128. doi:DOI: 10.1016/j.iccn.2017.07.006

Halimuddin, \& Atika. (2018). Kebutuhan Keluarga Pasien di Unit Perawatan Intensif. Jurnal Ilmiah Mahasiswa, 3(3), 315321. Retrieved from jim.unsyiah.ac.id > FKep > article $>$ download

Wardah. (2013). Dampak Hospitalisasi Pada Keluarga dan Peran Perawat Dalam Memenuhi Kebutuhan Informasi di Perawatan Intensif. Jurnal Husada Mahakam, 3(6), 263318. Retrieved 11 14, 2019, from https://docplayer.info/49476402 -Dampak-hospitalisasi-padakeluarga-dan-peran-perawatdalam-memenuhi-kebutuhaninformasi-di-perawatanintensif.html

Fadilah, A., \& Yusianto, W. (2019). Hubungan Kualitas Pelayanan Keperawatan Dengan Kepuasan Pasien Rawat inap Bedah Di RSUD dr. Loekmono Hadi Kudus. (S. Hartini, Ed.) Jurnal Keperawatan dan Kesehatan Masyarakat, 8(1), 35-44. Retrieved Maret 7, 2020, from : http://jurnal.stikescendekiautam akudus.ac.id/index.php/stikes

Frida, E. M., \& Putri, H. (2019). Hubungan Pelayanan Keperawatan Dengan Kepuasan Pasien BPJS Rawat Inap di Rumah Sakit Umum Herna Medan. Jurnal Darma Agung Husada, 6(2), 117-123. Retrieved Maret 7, 2020

Nugraha, K. I., \& Dody, S. (2019). Gambaran Kebutuhan Keluarga Pasien di ruang Instalasi Gawat Darurat. Jurnal Kepemimpinan dan Managment Keperawatan, 2(1), 34-39. doi:DOI: http://dx.doi.org/10.32584/jkmk. v2i1.198
Ahmad, J. (2018). Desain Penelitian isi (conten analysis).

Setyowati, E., Sulisetyawati, S. D., \& Saelan. (2019). Hubungan Perilaku Caring Perawat Dengan Kualitas Asuhan Keperawatan Pasien di Ruang ICU RSUD dr. Moewardi. 1-8.

Shalaby, S. A., Janbi, N. F., Mohammed, K. K., \& Al-harthi, K. M. (2018). Assessing The Caring Behaviors of Critical Care Nurses. Journal of Nursing Education and Practice, $\quad 8(10), \quad$ 77-85. doi:10.5430/jnep.v8n10p77

Hardayani, A., \& Lukmanulhakim. (2019). Predictor Of Nurses's Caring Behavior Towards Patients With Criticallllness. KnE Life Sciences, 12-22. doi:10.18502/kls.v4i13.5221

Sinclair, S., Beamer, K., Hack, T. F., Clement, S. M., Bouchal, S. R., Chochinov, M. H., \& Hagen, A. N. (2017). Sympathy, empathy, and compassion: A Grounded Theory Study of Palliative Care Patients' understandings, experiences, and preferences. Palliative Medicine, 31(5), 437447. doi:10.117/0269216316663499

Rizany, I., \& Hariyati, R. S. (2017). TeleICU Bermanfaat Dalam Pencapaian Pelayanan Berkualitas. Dunia Keperawatan, 5(1), 11-20. Retrieved juni 18, 2020

Hoonakker, P. L., \& Carayon, P. (2018). Work System Barriers and Stategies Reported By Tele-ICU Nurses: A Case Study Author Names and Degrees. HHS Public Access, 30(2), 259-271. doi:10.1016/j.cnc.2018.02.008

Oyira, James, E., \& E.R, E. (2016). Knowledge Practice and Outcome of Quality Nursing Care Among Nurses in Universty of Calabar Teaching Hospital 
(UCTH). (179-193, Ed.) Journal of Education and Training Studies, 4(11). doi:10.11114/jets.v4i11.1926

Zainal, R. A., Ake, j., \& Pasinringi, S. (2019). Hubungan Penerapan Proses Keperawatan Ida Jean Orlando Terhadap Peningkatan Kualitas Pelayanan di Ruang Perawatan Kritis IGD dan ICU RSUD Kabupaten Pangkajene dab Kepualauan. Jurnal Ilmiah Keperawatan, $5(1)$. doi:https://doi.org/10.33023/jike p.v5i1.208

Gaeeni, M., Farahani, M. A., Seyedfatemi, N., \& Mohamammadi, N. (2015). Informational Support to Family Members Of Intesive Care Unit Patients: The Perpectives of Families and Nurses. Global Journal of Health cience, 7(2), 819. doi:10.5539/gjhs.v7n2p8

Atika, \& Halimuddin. (2018). Kebutuhan Keluarga Pasien Di Unit Perawatan Intensif . JIM FKEP, 3(3), 315-321. Retrieved juni 19, 2020

Alsharari, A. F. (2019). The Need of Family members of Patiens Admitted to the Intensive Care Unit. Patient Preference and Adherence, 84(22), 465-478. Retrieved Juni 19, 2020, from www.dovepress.com

M, Z., Ma, N., \& Se, H. (2016). Needs Of Family Members of Critically III Patients in a Critical Care Unit at Universiti Kebangsaan Malaysia Medical Centre. Med\&Heath, 11(1), 11-21. doi:10.17845

Rusdianti, A., \& Arofiati, F. (2019). Kebutuhan Keluaga Pasien yang Dirawat Di Intensive Care Unit (ICU) : Literature Review. 2TRIK: Tunas-Tunas Riset Kesehatan, 9(1), 1-7. Retrieved Januari 20，2020， from https://www.researchgate.net/pu
blication/336285764_Kebutuha n_Keluarga_Pasien_yang_Dira wat_di_Intensive_Care_Unit_IC U_Literature_Review

Almagharbeh, W. T., Alhassan, M. A., Motlaq, M. A., \& Almagarbeh, R. T. (2019). Family Needs of Criticaly III patient in Central Jordan: A Family Perspective. American Journal of Biomedical Science\&Research, 1(5), 217221.

doi:10.34297/AJBSR.2019.01.0 0546

Aziz-Abdel, A. L., Ahmed Sayed, E. S., \& Younis, G. A.-H. (2017). Family Needs Of Critically III patients of Nurses and Family Perception. American Journal of Nursing Science, 6(4), 333-346. doi:10.11648/j.ajns.20170604.1 8

Dibsh, F., Gohal, B., \& Kherat, H. (2019). Engagement With Family in Critical Care Units: A Qualitatif Study. International Journal of Nursing, 6(2), 96-101. doi:10.15640

Chhetri, I. K., \& Thulung, B. (2018). Perception of Nurses on Needs of Family Members of Patient Admitted to Critical Care Units of Teaching Hospital Chitwan Nepal : A cross-Sectional Institutional Based Study. Nursing Research and Practice, 2018. doi: 10.1155

Apriyanti, E., \& Adawiyah, R. (2018). Kebutuhan Keluarga Saat Anak Dirawat Di Pediatric Intensive Care Unit (PICU): Sudut Pandang Keluarga dan Perawat. Jurnal Keperawatan Indonesia, 21(3), 159-168. doi:10.7454/jk1.v21i3.777

Fortunatti, C. P. (2014). Most Important Needs of Family Members Of Critical Patients in Light Of The Critical Care Family Needs Inventory. Invest Educ Enferm, 
$32(2)$,

306-216.

doi:10.1590/S0120-

53072014000200013

Fateel, E. E., \& O'Neill, C. S. (2015).

Family Member's Invovement in The Care of Critically ill Patients in Two Intensive Care Units in a Acute Hospital in Bhrain; The Experiences and Perspectives of Family members' and Nurses'- A Qualitative Study. Clinical Nursing Studies, 4(1), 57-69. doi:10.5430/cns.v4n1p57 
